\title{
CAMBIO INSTITUCIONAL Y CAMBIO ECONÓMICO EN LA ESPAÑA DEL SIGLO XIX
}

\author{
PEDRO TEDDE \\ Servicio de Estudios del Banco de España
}

\begin{abstract}
RESUMEN
Los cambios institucionales que definieron la revolución liberal en Occidente tuvieron efectos positivos sobre el crecimiento económico. La igualdad de los individuos ante la ley, la simplificación de la administración de justicia, la definición clara de los derechos de propiedad y la apertura del mercado contribuyeron a una rápida aproximación entre las expectativas de una mayor rentabilidad individual y el logro del incremento de rentabilidad social. En el presente artículo se examina el cambio institucional operado en la España del siglo xIx, y se concluye con la afirmación de que los defectos en su práctica no aportaron todas las consecuencias favorables al crecimiento económico que cabía esperar del nuevo sistema.
\end{abstract}

\begin{abstract}
The institutional changes which emerged from the liberal revolution of Westem Europe were beneficial for economic growth. Equality before the law, the simplification of the judiciary, the defining of clearer property rights, and the opening of the market all contributed to a rapid approximation of the expected improvements in private returns with the increase in social returns. This article examines the institutional changes that took place in nineteenth century Spain, and concludes that deficiencies in the carrying out of the reforms produced smaller gains for economic growth than might have been expected.
\end{abstract}

\section{CAMBIO INSTITUCIONAL, LIBERALISMO Y MODERNIZACIÓN ECONOMICA}

Existe una opinión extendida acerca de las consecuencias positivas que, para el crecimiento económico moderno de una sociedad determinada, tiene 
la adopción del sistema político liberal. Sin ánimo de realizar una enumeración exhaustiva de tales consecuencias, cabe destacar los efectos plausibles de algunos de los cambios institucionales inherentes a dicho modelo de sociedad 1.

Desde Adam Smith, se admite generalmente que la ampliación del mercado conduce a la especialización económica, y ello, a su vez, genera incrementos de productividad, debido, sobre todo, a la generación de economías de escala. La actividad de mercado existió, al menos, veinticuatro o veinticinco siglos antes del triunfo del mercantilismo en el norte de Europa, de la Revolución Francesa o de la independencia de los Estados Unidos. Pero resulta indudable que la implantación del modelo liberal de sociedad contribuyó decisivamente a ensanchar el mercado - así ocurrió en España- cuando fueron derribadas las barreras legales que impedian la enajenación de propiedades pertenecientes a determinadas instituciones, como la Iglesia o los mayorazgos.

La revolución liberal ha tenido, como efecto común en las sociedades occidentales, la homogeneidad jurídica y la igualdad de los individuos ante las instituciones. Ello ha revertido en una notable reducción de los costes de transacción en la actividad de mercado, al eliminarse peculiaridades normativas o jurídicas, por regiones o estamentos. Así, la generalización del sistema métrico decimal, la supresión de procedimientos judiciales específicos para la nobleza, la universalidad de los códigos, la desaparición de las aduanas interiores y la unificación de la moneda se tradujeron en mayores facilidades para los intercambios. Sin embargo, es preciso hacer dos observaciones. La primera se refiere al conflicto potencial que puede generarse en una sociedad con peculiaridades juridicas, si éstas son suprimidas en aras de una mayor uniformidad con el resto de las regiones y comunidades, es decir, debido a la homogeneidad normativa que trata de imponer el Estado liberal. En España, baste recordar las consecuencias sociopolíticas que trajo consigo la supresión de los fue$\operatorname{ros}^{2}$.

La segunda observación se refiere, precisamente, a la aparición de costes de transacción que interfieren las relaciones económicas entre los sujetos económicos, y que en gran parte dependen del ordenamiento institucional. Desde nuestro punto de vista, la manera en que se llevó a cabo la revolución liberal, en las diferentes naciones, pudo influir, de hecho, en la aparición de tales cos-

1 Una primera versión de este trabajo fue presentada en el homenaje que se llevó a cabo en la Universidad Autónoma de Madrid, en marzo de 1993, al profesor Miguel Artola. Dicha version ha sido publicada dentro del volumen A. M. Bernal y otros (1994). El autor agradece todos los comentarios y críticas recibidas, especialmente por Concepción de Castro y el resto de los intervinientes en el Seminario de Historia Contemporánea celebrado en marzo de 1994, en la Fundación Ortega y Gasset.

2 Artola (1978), pp. 280-282. 
tes. Son numerosos los especialistas que se han ocupado de estas cuestiones, tanto desde un punto de vista teórico como histórico, y ello supone la revisión de algunos supuestos del análisis neoclásico. Como explican North y Thomas, el crecimiento de la renta per capita, verdadera medida del crecimiento económico, depende de dos condiciones. La primera, que se incrementen las cantidades per capita de factores productivos. La segunda, un aumento de eficacia por parte de uno o más factores de la producción. Esta última condición procederá, a su vez, de la realización de economías de escala, debido a la elevación de la calidad de los factores, tales como una mejora del capital humano, debido a más educación o entrenamiento laboral, o del capital físico, gracias a una nueva tecnología, o a reducciones de las imperfecciones del mercado, por ejemplo, costes de incertidumbre e información, o a cambios en la organización económica ${ }^{3}$. North, recientemente, ha insistido en que la existencia de los costes de transacción o de entrada desmiente la hipótesis del crecimiento económico basado exclusivamente en la integración de unidades económicas en mercados amplio y en el acceso libre a la tecnología. ${ }^{4}$

Los costes de transacción aparecen en todas las relaciones de mercado, pero su magnitud dependerá del ordenamiento institucional que se aplica en la sociedad. Hay costes de transacción ex ante (redacción de contrato, negociación, búsqueda de oferentes o de demandantes, acceso a la información del mercado) y ex post (discusión sobre el precio, perjuicios por infracción de contrato, aseguramiento y solicitud de apoyo partidista o gubernamental del

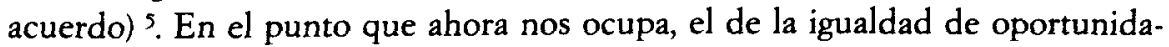
des de los individuos ante la ley, a consecuencia de la reforma liberal, cuanto mayor sea la presión potencial de determinados individuos o grupos sobre las instituciones que dictan la norma, o dirimen los conflictos, mayor será la probabilidad de que los costes de transacción crezcan. Evidentemente, la creación de una normativa que contribuya a reducir tales costes, asi como de unos órganos sociales competentes para vigilar el cumplimiento - y sancionar el incumplimiento- de dichas normas, forma parte de las funciones básicas del Estado y tiene indudables repercusiones sobre el crecimiento económico. Aqui no sólo cabria situar la generación de mecanismos sociales eficaces para hacer que los contratos sean debidamente respetados o evitar las prácticas monopolistas de individuos o grupos de presión. También deberian incluirse las inversiones sociales dirigidas a minimizar los costes de información y entrada, por ejemplo, la educación. La instrucción, pública o privada, no sólo tiene

\footnotetext{
'North y Thomas (1971), pp. 777-803, North (1984), pp. 18-19.

4 North (1990), p. 135.

5 Williamson (1985), pp. 25-32, y Eggertsson (1990), pp. 101-102.
} 
consecuencias sobre la capacidad productiva, sino también sobre la posibilidad y capacidad de participación en los intercambios.

La revolución liberal trajo consigo una característica definición de los derechos de propiedad, en la cual los derechos individuales alcanzan un relieve especial, pero sin que ello implique la desaparición de los derechos comunales o colectivos ${ }^{6}$. Según North y Thomas, la defensa y protección de los derechos de propiedad competen al Estado, en un sistema liberal, porque éste puede hacerlo a un coste inferior al que soportarian los individuos particulares o los grupos privados 7 . En todo caso, la definición rigurosa de los derechos de propiedad tiende a estimular la inversión de los propietarios, o usuarios, de los recursos productivos y aproximará la tasa de beneficio potencial del sistema económico a la efectiva o, como dice Eggertsson, acercará la frontera estructural a la frontera técnica de la producción ${ }^{8}$.

Evidentemente, una definición imperfecta de los derechos de propiedad -individuales y no individuales - tendrá los efectos contrarios. La inversión, en este caso, se retraerá y las posibilidades de crecimiento económico serán inferiores a las que el acceso a la tecnologia disponible y los recursos financieros disponibles permiten.

Además de la ampliación del mercado, de la igualdad jurídica de los individuos, de la reducción de los costes de transacción y entrada, de la mejor definición de los derechos de propiedad, hay un último aspecto del cambio institucional -en el caso de la reforma liberal- que tenemos en cuenta, en relación con el cambio económico. Se trata de la elección social de un sistema tributario, y de un nivel determinado de presión fiscal, así como, paralelamente, de una distribución concreta del gasto público, según unas funciones y órganos definidos. En este punto confluyen el afianzamiento de la idea de la soberanía popular con la conciencia de que el Estado debe disponer de unos recursos dados para afrontar necesidades sociales, sin que otros poderes -Iglesia, nobleza - tengan facultades para recabar ingresos y determinar gastos colectivos. No es casual que en el origen de algunas de las más significadas revoluciones liberales se encuentren problemas de naturaleza fiscal, como tampoco lo es el hecho de que algunos de los más eminentes historiadores del liberalismo dediquen considerables esfuerzos al estudio de la transición de la Hacienda del Antiguo Régimen a los modernos sistemas tributarios. Sin un control eficaz, por parte de la sociedad, de la asignación de los ingresos impositivos, y de la consiguiente cuantificación y distribución del gasto público, re-

- Alchian y Demsetz (1973), pp. 16-27.

7 North y Thomas (1973), pp. 5.16.

8 Eggertsson (1970), p. 319. 
sultaria inviable la creación de unos mecanismos institucionales capaces de garantizar la homogeneidad juridica de los ciudadanos y de reducir los costes de transacción. Y también es cierto, a la inversa, que, sin una efectiva igualdad de oportunidades y sin instituciones adecuadas para corregir injusticias o errores en el desenvolvimiento de la actividad social, sería improbable la determinación de un sistema fiscal dotado de suficiencia y equidad. Ello nos conduce a la constatación de que los cambios institucionales inherentes a la reforma liberal están mutuamente condicionados.

\section{LOS CAMBIOS INSTITUCIONALES EN EL LIBERALISMO ESPAÑOL}

Resulta dificil comprobar las consecuencias que sobre la modernización económica de España del siglo XIX tuvieron los cambios institucionales del liberalismo. En primer lugar, y desde un punto de vista metodológico general, como tempranamente observaron los críticos de la nueva historia institucional, las explicaciones sobre la interconexión entre factores políticos o sociales y económicos son difícilmente contrastables por procedimientos cuantitativos. De esa manera, resulta ardua la definición rigurosa de una precisa relación causal entre una variable institucional y otra económica, tanto más cuando no hay comportamientos univocos de sujetos o grupos, en la historia, ante los mismos cambios 9. En segundo lugar, y ya en el caso concreto de España, hay que considerar que la gestación institucional del liberalismo fue dilatada y contradictoria, pudiéndose situar sus límites cronológicos en las Cortes de Cádiz, por un lado, y en el sexenio revolucionario 1868-1874, por otro. En tercer lugar, la revolución liberal coincidió, en el caso español, con otros dos importantes cambios históricos. Uno de estos cambios fue la pérdida de casi todos los territorios americanos entre 1810 y 1824 , sobre cuyas consecuencias económicas se ha abierto un interesante debate ${ }^{10}$. Por otra parte, España atravesó un largo periodo de guerras, casi ininterrumpido, a lo largo de treinta años, desde la confrontación de la Monarquia de Carlos IV con la Convención francesa hasta los vanos esfuerzos por contener el movimiento de emancipación hispanoamericana. Josep Fontana ha cuantificado con nitidez el coste financiero de estas guerras. En 1808, antes del enfrentamiento con los ejércitos napoleónicos, la deuda interior del Estado acumulada era de 7.198,7 millones de reales, de los

\footnotetext{
9 Fishlow y Fogel (1971).

10 Sardá (1987); Fontana (1970), 1971), (1982) y (1991); Prados de la Escosura (1993).
} 
cuales el 71,2 por 100 correspondia al reinado de Carlos IV, periodo éste, de 1788 a 1808 , en el que se sucedieron las guerras contra Francia e Inglaterra. En 1820, la deuda interior del Estado casi se había duplicado alcanzando 13.120,5 millones de reales. De esta suma, el 48,1 por 100, 6.305,8 millones, correspondería, según Fontana, a gastos impagados durante la guerra de Independencia y a intereses pendientes de la deuda pública. Después de 1828, del cómputo de la deuda interior desaparecieron, sin justificación, más de 7.000 millones de reales, lo que se explicaria por la liquidación unilateral y arbitraria por el gobierno de las obligaciones contraídas al final del Antiguo Régimen con sus acreedores nacionales, sobre todo, con los proveedores de los ejércitos que combatieron en la guerra de Independencia "1. Ello nos lleva a dos conclusiones, por un lado, la financiación de las guerras al final del Antiguo Régimen, recayó de manera desigual sobre los diversos contribuyentes y sectores económicos de la nación. Por otra parte, a pesar de la brusca reducción de la deuda, a finales de los años veinte, la sociedad española habría de soportar, durante muchos decenios, una pesada carga financiera. Quiere esto decir que, coincidiendo con las posibles consecuencias del cambio politico, la economia española del siglo XIX experimentaría, de manera simultánea, los efectos - siquiera a corto o medio plazo- de la emancipación hispanoamericana y del endeudamiento del Estado, representando esta carga financiera, probablemente, más del 150 por 100 de la Renta Nacional de finales del siglo XVIII ${ }^{12}$. Naturalmente, además de los efectos provocados por dichos cambios, debemos destacar la influencia determinante que sobre la evolución de la economía en el siglo XIX tuvieron el crecimiento de la población, la vinculación con el mercado internacional, las importaciones de capital y la adopción de tecnología moderna. Todo ello hace prácticamente imposible el intento de cuantificar las consecuencias del cambio institucional sobre la economía española, pero, al menos, se pueden plantear algunas hipótesis explicativas para establecer dichas hipótesis se intentará relacionar algunas de las regularidades y deducciones explicadas por los nuevos historiadores institucionales con las interpretaciones que algunos historiadores contemporáneos han hecho acerca de las reformas liberales en España.

Para delimitar el objeto de la cuestión que nos ocupa, las consecuencias económicas del cambio institucional representado por la revolución liberal, podemos atenernos al periodo 1833-1875, esto es, desde la Regencia de la reina Maria Cristina, en la minoría de edad de Isabel II, a la Restauración de Al-

11 Fontana (1973), pp. 198-228, y Fontana y Garrabou (1986), p. 102.

12 Tomo los datos de los cálculos de Prados de la Escosura (1993), pp. 271-176. 
fonso XII. En este periodo ya se habian superado los efectos deflacionistas de la interrupción de los intercambios con el continente americano, y, como se ha visto más arriba, se habia eliminado, de manera expeditiva, la mayor parte de las cargas financieras contraidas al final del Antiguo Régimen ${ }^{13}$.

Seguidamente examinaremos la manera en que se llevaron a la práctica los principales cambios institucionales de la reforma liberal en España, que pudieron tener repercusiones en el crecimiento económico: ampliación del mercado, igualdad de los individuos ante la ley, redefinición de los derechos de propiedad, reducción de los costes de transacción y entrada, y determinación por los representantes de los ciudadanos de los ingresos y gastos del Estado ${ }^{14}$.

La ampliación del mercado, a raiz de la revolución liberal, tuvo en España varias manifestaciones. La supresión de los gremios y la extinción de la Mesta contribuyeron a eliminar barreras en el mercado de la tierra y en el sector manufacturero. Pero fueron, sobre todo, el proceso desamortizador, empezado en 1798 y prolongado hasta la segunda mitad del siglo xIx, y la abolición del mayorazgo en 1836, y de manera definitiva en 1841, las medidas que liberalizaron el mercado de bienes raices. Cabe suponer que la agricultura española experimentó un incremento durante la primera mitad del siglo XIX, esto es, durante la época en que se llevó a cabo la desamortización eclesiastica ${ }^{15}$. Ello permitió, como ha señalado Gonzalo Anes, el aumento de la población a la vez que se llevaba a cabo un comercio de exportación de productos alimenticios. La población creció, entre 1800 y 1857 casi un 35 por 100 . Este mismo autor recuerda que las tierras de la Iglesia eran las mejores y que, según algunos testimonios, muchas propiedades eclesiásticas permanecian yermas ${ }^{16}$. De hecho, una vez consumado el ciclo desamortizador de Mendizábal y Espartero, las nuevas roturaciones se harian en tierras de calidad inferiores y los rendimientos medios tendieron a decrecer, especialmente en el cultivo de cereal. De los datos que aporta Gabriel Tortella en una reciente síntesis de historia económica contemporánea, se deduce que la última etapa en la cual se vendieron bienes del clero por un importe considerable, 1858-1867 (1.253 millones de reales, frente a 3.447 millones en 1836-1844), coincide con el periodo en que la producción de trigo por habitante llegó a su máximo nivel, en el siglo XIX ${ }^{17}$. Tortella subraya cómo, además de los cambios en la estructura de la propiedad, otras innovaciones introducidas en la economía española, por ejemplo, la

13 Sardá (1987), pp. 243.248.

14 Para una visión más detallada de estos cambios, véase Tedde (1994).

15 Tortella (1994), pp. 51.54.

16 Anes (1970), pp. 235.263.

17 Tortella (1994), pp. 44-54. 
construcción del ferrocarril o el aumento de la población, pudieron influir en los incrementos en la producción y productividad agrarias. Pero, de la información disponible, parece confirmarse que la enajenación de los patrimonios antes amortizados - sin olvidar la abolición de los mayorazgos, con la consiguiente movilidad de las propiedades nobiliarias-, y la extinción de la Mesta, debieron repercutir de manera positiva sobre la eficiencia de la economia española.

$\mathrm{La}$ igualdad jurídica de los ciudadanos, ante la ley y ante los tribunales, proclamada por las Cortes de Cádiz, representó una reducción de los costes de transacción, al simplificarse los procedimientos de reclamación de obligaciones contractuales y universalizó las jurisdicciones ante las cuales presentar los litigios. Así, el fin de los mayorazgos, probablemente, tuvo como consecuencia una reducción de los costes de transacción, al agilizarse los trámites en las reclamaciones ante los tribunales por deudas de sujetos pertenecientes a la nobleza. En concreto, los acreedores, en los casos de suspensión de pagos de antiguos titulares de patrimonios vinculados, pudieron ejercer sus derechos con mayor presteza y seguridad a raiz de la reforma liberal ${ }^{18}$.

Sin embargo, la igualdad ante la ley y los tribunales fue, a veces, más teórica que real. Lo demuestra la manera en que se llevó a cabo el desmantelamiento del régimen señorial. En España los señorios territoriales se convirtieron en propiedad libre, correspondiendo en adelante dicha propiedad al antiguo titular del señorio y los señorios jurisdiccionales desaparecieron, en beneficio de la autoridad del Estado, cesando, por tanto, la obligación de efectuar pagos y prestaciones. Miguel Artola ha explicado la larga serie de conflictos sociales y pleitos a que dio lugar este cambio institucional. Por un lado, hubo casos en que el antiguo señor reclamó como propiedad privada bienes comunales y baldíos. Por otro, se trató de confundir las prestaciones dimanadas del señorío jurisdiccional con el pago de la renta de la tierra, característico del régimen de arrendamiento ${ }^{19}$. Salvador de Moxó, en un libro que trata de la disolución del régimen señorial en España, afirma que, frecuentemente, en los antiguos señorios jurisdiccionales, los agricultores pasaron de ser cultivadores hereditarios y poseedores perpetuos de sus explotaciones a convertirse en colonos temporales. No sólo se mantenía, de esta manera, la obligación de realizar pagos al antiguo señor, este último ahora como propietario de las tierras presuntamente arrendadas, sino que se rompía el nexo jurídico del labriego con su heredad, dándose la posibilidad de ser desplazado de la explotación ${ }^{20}$. En otras palabras, el campesino, que hubiera debido convertirse tras la disolu-

18 Tedde (1988), p. 39.

19 Artola (1978), pp. 171-174 y 225-227.

20 Moxó (1965), p. 86. 
ción de los señorios jurisdiccionales en propietario de pleno derecho, pasaba a ser un mero arrendatario, sin la seguridad del dominio perpetuo de la explotación y sin las facultades derivadas de la propiedad, como las de enajenar o transmitir. Los conflictos entre señores y comunidades de campesinos se plantearon ante las Cortes y ante los tribunales, y en muchos casos se prolongaron a lo largo de decenios. Moxó señala el hecho de que la jurisprudencia, general. mente, se inclinó a favor de los titulares antiguos de señorios, o sus sucesores. Este autor subraya la circunstancia de que algunas de las sentencias, contrarias a los intereses de los campesinos, se dictaron en periodos de gobierno liberal de signo revolucionario o radical, como el sexenio 1868-1874. Los debates sobre la reforma agraria, durante los años de la Segunda República, recogieron los antiguos agravios de los campesinos por esta causa. Claudio Sánchez-Albornoz se refiere al «enorme fraude que se cometió a mediados del siglo XIX, fraude al cual ayudaron los Tribunales españoles» ${ }^{21}$.

La decantación del sistema judicial a favor de los intereses de los antiguos señores distorsionó la hipotética igualdad jurídica de los ciudadanos y tuvo como consecuencia el distanciamiento de amplias capas de la sociedad del régimen liberal, y aun la radicalización política, en uno u otro sentido, del campesinado ${ }^{22}$. Recientemente, Antonio Miguel Bernal ha puesto de relieve las diferencias existentes, en esta cuestión, entre la disolución del régimen señorial en España y el modelo de reforma liberal seguida en Francia. El mismo autor subraya la tardanza del proceso, en el caso español, y la aparición de secuelas - cuando se dio por cerrado-durante más de un siglo ${ }^{23}$.

Esta misma cuestión nos conduce al examen, en el caso español, de otras de las transformaciones características de la reforma liberal: la redefinición de los derechos de propiedad. La seguridad que otorga la propiedad consagrada por la ley y a resguardo de arbitrariedades o interferencias ajenas debió favorecer la inversión, y por tanto el aumento de productividad. Tanto más debió darse este fenómeno en los casos de nuevos propietarios con recursos elevados, como ha explicado Richard Herr en los casos que ha estudiado de desamortización ${ }^{24}$. Por el contrario, la indefinición de los derechos de propiedad, tanto sobre los bienes comunales como sobre las explotaciones individuales, a lo largo de un período dilatado de tiempo, debió tener el efecto contrario, desalentando las inversiones, especialmente las más costosas, y manteniendo, por tanto, la productividad por debajo de su nivel potencial.

21 Sánchez-Albornoz (1932), p. 19.

22 Fontana (1974), pp. 162-165 y Nadal (1975), pp. 62-67.

23 Bernal (1994), pp. 76-84.

24 Herr (1974) y (1991). 
En España fue relativamente temprana la adopción de normas que favorecen la fluidez en los intercambios y proporcionan seguridad a los inversores, y en general a los intervinientes en la actividad de mercado, es decir, que tienden a reducir costes de transacción. Resulta significativo que durante el último decenio del reinado de Fernando VII —en plena reacción antiliberal, por tanto- se promulgara una serie de normas que iban dirigidas a facilitar las relaciones mercantiles y las innovaciones productivas. En 1826 se reglamentó el sistema de patentes ${ }^{25}$. En 1829 se promulgó el primer Código de Comercio, el cual fijaba una jurisdicción que afectaba a todos los actos de esta naturaleza, sin atender a la condición de las partes, y se disponía la creación de registros mercantiles. En ese mismo año se fundaba, en la capital del reino, el Banco de San Fernando, y dos años más tarde comenzaba su actividad la Bolsa de Madrid. Sin duda alguna, estas dos últimas instituciones fueron creadas con la finalidad preferente de procurar recursos financieros al Estado, pero, siquiera en pequeña medida, con ello se agilizaron los intercambios de activos financieros y la generación de medios de pago. Como ocurriría en las décadas centrales del siglo $\mathrm{xx}$, podía coexistir un régimen político de signo antiliberal con la promulgación de normas favorecedoras de la actividad de mercado. No cabe descartar, en uno y otro caso, que esos primeros pasos por la senda de la libertad económica y la igualdad ante el mercado acabaran reclamando la necesidad de cambios institucionales más profundos. Por otra parte, la permanencia de ordenamientos juridicos forales hasta finales del siglo xIX pudo representar un nivel de costes de transacción superior al de otros países. Sin embargo, en los aspectos del ordenamiento civil con contenido más económico, se dictaron normas especiales de alcance general, como la Ley Hipotecaria de 1861. En una dirección homogeneizadora, hay que mencionar también la unificación del sistema monetario y el de pesos y medidas.

Asimismo, al tener en cuenta la existencia de costes de transacción e información susceptibles de ser reducidos por el Estado, debemos considerar la tardanza relativa en la construcción de los ferrocarriles en España, lo cual suponía la permanencia de una dificultad física indudable para las relaciones de mercado a lo largo de varios decenios ${ }^{26}$. También la insuficiencia del sistema educativo público, más grave en España que en otros países europeos, debió repercutir en una deficiente formación de capital humano, y en la subsistencia de barreras de entrada a la innovación técnica, a la inversión y al mercado ${ }^{27}$.

25 Sáiz González (1993).

26 Artola (dir.) (1978), Gómez Mendoza (1982).

27 Núñez (1992). 
En tercer lugar, la infradotación de recursos destinados a la administración de la justicia - con evidente repercusión sobre la resolución de conflictos económicos- queda de manifiesto si se observa cómo dichos recursos, en términos proporcionales, crecieron sólo la mitad de lo que aumentó el gasto público total, entre 1845 y 1860 . Y ello ocurrió después de que, entre 1830 y 1840 , el gasto total decreciera en términos absolutos ${ }^{28}$.

Esta evidencia nos conduce a la reforma liberal del sistema tributario y de la política de gasto público. En primer lugar, como han observado, entre otros, Enrique Fuentes Quintana, Miguel Artola y Francisco Comin, la modernización del sistema tributario sufrió, en España, un evidente retraso, manteniéndose durante casi toda la primera mitad del siglo XIX un cuadro fiscal con reminiscencias del Antiguo Régimen ${ }^{29}$. Tras la reforma de 1845 -que permanecería casi invariable, en sus rasgos fundamentales, durante más de medio siglo- quedaron en evidencia defectos tales como la insuficiencia, la rigidez y la falta de equidad en el reparto de la carga tributaria ${ }^{30}$. El carácter oligárquico de la sociedad española del xIX, puesta de manifiesto en la reforma del régimen señorial, a la que se ha hecho referencia más arriba, tuvo su correlato en el diseño del sistema fiscal. No sólo los más poderosos tenían mayores posibilidades de eludir parte de sus obligaciones tributarias, dado el modo de repartir el importe de la principal figura impositiva, la contribución sobre el producto agrario y de los inmuebles. Además, había actividades económicas muy productivas, apenas afectadas por impuestos. Asimismo, el peso relativo de la contribución indirecta, generalmente considerada más regresiva que la directa, era muy elevado. El resultado fue el déficit crónico de los presupues. tos, la necesidad de endeudamiento del Estado y, según se pudo comprobar al cabo del tiempo, un volumen considerable de defraudación. La precisión de pagar todos los años una cantidad elevada de intereses de la deuda hizo que otras partidas del gasto público quedaran constreñidas a unas proporciones relativamente modestas en comparación con otros países europeos. Las consecuencias negativas sobre la modernización económica son obvias ${ }^{31}$. Hay que considerar, en este punto, que el caso español no es único. Como ha observado Gabriel Tortella, el sistema liberal en los paises del sur de Europa -España, Portugal, Italia - durante el siglo xIX, y primera mitad del Xx, era frágil y estaba defectuosamente ensamblado. Uno de los aspectos en el que más se manifiestan tales defectos es el sistema financiero del Estado. En la Europa meri-

\footnotetext{
28 Comin (1985).

29 Artola (1986), Fuentes Quintana (1990), Comin (1988) y (1990).

30 Fuentes Quintana (1990), Tedde (1984).

31 Tedde (1985), Comin (1988).
} 
dional la naturaleza oligárquica de la organización política mantenía apartada de las determinaciones colectivas a la gran mayoria de la sociedad. Además, la baja productividad de la economia, la radicación rural de la mayor parte de la población y la reducida renta per capita dificultaban el acceso a la información y a los centros de decisión política. De esa manera se producía una interacción entre la lentitud del crecimiento económico y la imperfección de la organización política ${ }^{32}$.

Podemos concluir recordando que en España, como en otros paises del sur de Europa, la economía se modernizó durante el siglo XIX, aunque a un ritmo insuficiente, de manera que la aproximación a las economías del Norte no se produciria hasta ya entrado el siglo xx. Se han aducido a factores como el clima mediterráneo y la excesiva altitud de muchas superficies cultivadas, la escasez de empresarios eficaces, y la casi nula integración de la industria en los mercados externos, como claves explicativas del atraso económico español. También hay que considerar causas institucionales, relacionadas con las circunstancias mencionadas. En España, como en otras naciones, la reforma liberal se llevó a cabo con resultados contradictorios, por lo que se refiere a su repercusión en la modernización económica. Ni se redujeron en su debido alcance los costes de información y transacción ni quedaron claramente definidos los derechos de propiedad durante un largo periodo, ni la organización financiera del Estado respondió a las necesidades de la nueva sociedad. No significa esto que la revolución liberal no hubiera debido realizarse ni que su influjo fuera totalmente negativo para la economía. La reforma liberal que se dio en la España del siglo XIX tuvo, probablemente, más consecuencias positivas que negativas, lo cual no debe ocultar las imperfecciones y las carencias de algunos cambios institucionales. De modo semejante, hubo cambio económico, aunque a un ritmo excesivamente lento. De este modo, se correspondería un crecimiento económico gradual con una modernización política inconclusa.

\section{BIBLIOGRAFÍA}

Alchian, Armen A., y Demsetz, Harold (1973): «The Property Right Paradigm», en Journal of Economic History, XXXI 1 (March), pp. 16-27.

ANES, Gonzalo (1970): «La agricultura española desde comienzos del siglo xIX hasta 1868», en Pedro Schwartz (coord.), pp. 235-263.

Anes, ARtola, FonTANa y TEDde (1982): La economía española al final del Antiguo Régimen, 4 vols., Madrid, Alianza.

32 Tortella (1994), pp. 24-28. 
Artola, Miguel (1978): Antiguo Régimen y revolución liberal, Barcelona, Ariel.

- (1985): La Hacienda del siglo XIX, Progresistas y moderados, Madrid, Alianza.

BERNAL, Antonio Miguel (1994): «Antiguo Régimen y transformación social», en Bernal, A. M., y otros, pp. 69-86.

Bernal, Antonio Miguel, y otros (1994): Antiguo Régimen y liberalismo, Madrid, Alianza. Bonilla, Heraclio (ed.) (1991): El sistema colonial en la América española, Barcelona, Crítica.

ComfN, Francisco (1985): Fuentes cuantitativas para el estudio del sector público en España, 1801-1980, Madrid, Instituto de Estudios Fiscales, monografía núm. 40.

- (1988): Hacienda y Economía en la España contemporánea, 2 vols., Madrid, Instituto de Estudios Fiscales.

- (1990): Las cuentas de la Hacienda preliberal en España (1800-1855), Madrid, Banco de España, Servicio de Estudios.

EgGertsson, Thrainn (1990): Economic Behavior and Institutions, Cambridge, Cambridge University Press.

FISHLOW, Albert, y FOGEL, Robert W. (1971): «Quantitative Economic History: An Interim Evaluation. Past Trends and Present Tendencies», en Joumal of Economic History, XXXI, 1 (March), pp. 15.42.

FONTANA, Josep (1970): «Colapso y transformación del comercio exterior español entre 1792 y 1827. Un aspecto de la crisis de la economia del Antiguo Régimen en Españan, en Moneda y Crédito, 115, pp. 3-23.

- (1971): La quiebra de La monarquia absoluta, 1814-1820, Barcelona, Ariel.

- (1973): Hacienda y Estado, 1823-1833, Madrid, Instituto de Estudios Fiscales. (1974): Cambio económico y actitudes políticas, Barcelona, Ariel.

- (1982): «Comercio colonial y crecimiento económico: revisiones e hipótesis», en Anes, Artola, Fontana y Tedde (eds.), vol. III, Comercio y colonias, pp. XI-XXXIV.

- (1991): «La crisis colonial en la crisis del Antiguo Régimen español», en Bonilla (ed.), pp. 305-320.

Fontana, J., y Garrabou, R. (1986): Guerra y Hacienda, Alicante, Instituto Juan Gil-Albert.

Fuentes Quintana, Enrique (1990): Las reformas tributarias en España, Barcelona, Crítica.

HERR, Richard (1974): «El significado de la desamortización en España», Moneda y Crédito, 131, pp. 55-94.

(1991): Hacienda Real y cambios rurales en España a finales del Antiguo Régimen, Madrid, Ministerio de Economía y Hacienda.

Martin Aceña, Pablo, y Prados de la Escosura, Leandro (eds.) (1985): La Nueva Historia Económica en España, Madrid, Tecnos.

Moxó, Salvador de (1965): La disolución del Antiguo Régimen en España, Madrid, CSIC.

NADAL, Jordi (1975): El fracaso de la revolución industrial en España, 1814-1913, Barcelona, Ariel.

NorTh, Douglas N. (1984): Estructura y cambio en la bistoria económica, Madrid, Alianza (ed. en inglés, W. W. North and Co., 1981).

- (1990): Institutions, institutional change and economic performance, Cambridge, Cambridge University Press.

NorTH, D. C., y ThOmas, R. P. (1971): «The Rise and Fall of the Manotial System: A Theoretical Model», Journal of Economic History, XXXI, 4, pp. 777-803.

- (1973): The Rise of the Western World. A New Economic History, Cambridge, Cambridge University Press.

Núnez, Clara Eugenia (1992): La fuente de la riqueza, Madrid, Alianza. 
Prados DE la Escosura, Leandro (1993): «La pérdida del imperio y sus consecuencias económicas en España», en Prados de la Escosura y Amaral (eds.), pp. 253-300.

Prados dE LA Escosura, Leandro, y Amaral, Samuel (eds.) (1992): La independencia americana: consecuencias económicas, Madrid, Alianza.

SARDA, Juan (1987): Escritos, Madrid, Banco de España.

SCHWARTZ, Pedro (ed.) (1970): La economia española a mediados del siglo XIX, Barcelona, Madrid.

TEDDE, Pedro (1984): «Aproximación al cuadro tributario de la Restauración», en $\mathrm{Ha}$ cienda Pública Española, 87, pp. 323-338.

- (1985): «El gasto público en España, 1875-1906: un examen comparativo con las economias europeas», en P. Martín Aceña y L. Prados de la Escosura (eds.), pp. 233-261.

- (1988): El Banco de San Carlos, Madrid, Alianza.

- (1994): «Revolución liberal y crecimiento económico», en A. M. Bernal y otros, pp. 31-49.

Tortella, Gabriel (1994): El desarrollo de la España contemporánea, Madrid, Alianza.

Williamson, Oliver E. (1985): Las instituciones del capitalismo, México, Fondo de Cultura Económica (ed. en inglés, The Free Press, 1985). 